\title{
The comfort of 1000 words
}

Ho Manh Toan

Phenikaa University

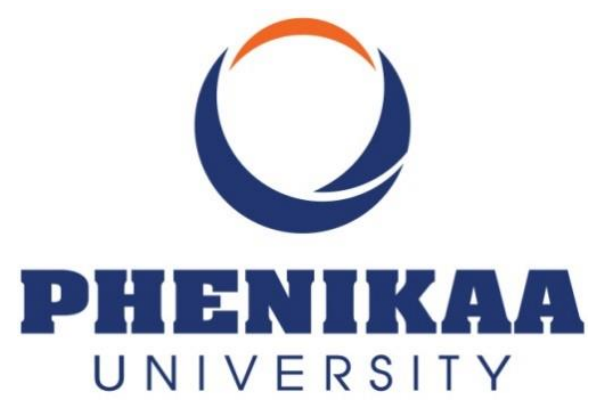

February 7, 2021

It is common to think that a long ball is the shortest way to the goal. However, a long ball provides several hiccups: harder to control, stamina draining, or the 50/50 fight. Thus, Johan Cruyff or Pep Guardiola prefers the short-or-middle pass. The long ball is used more calculatedly and has a specific tactical connotation.

Scientific communities champion the original research article. The 6000-word essay has a make-or-break effect on many people's careers. Indeed, in a traditional IMRaD format, 6000 words are adequate to present new results, argue a viewpoint, or introduce a new idea. There is nothing wrong with the original research article or even the book. However, just like a long ball, these long formats of scientific writings also have some hiccups.

It is not easy to write 6000 words. Do you remember how you ground your term papers back to your alma mater? Sometimes, writing a scientific paper is no different. The process of writing an original research paper involves many stages that you need three to five years to learn. Generally, researchers need to know research design, literature review, data collection, data analysis. For natural sciences, there are also lab works with rigorous protocols. Eventually, writing a 6000 -word paper is an accumulation of a long process. It is fun, but like anything you do toward the end, it is not easy to maintain the motivation. 
Writing a 6000-word paper is time-consuming, and reading it is time-consuming too. Considering the preparation is finished, the writing process probably takes around two weeks, with another week for editing. That is generous. I think it is usually more rushing. Meanwhile, the reading of these papers can be quite painful too. It is no coincidence that top scientific journals also publish articles about how to read a paper [1] or complaining about the difficulty of scientific papers [2].

That is why I find my comfort in writing a 1000-word essay every day. I have been doing it recently, and it certainly brings a soothing feeling. If writing a 6000-word paper is a finishing move, writing a 1000-word is a pass that sets up a sequence of events. Michael Cox wrote about Xavi:

"His passes are laced with information about what the recipient should do next - slow passes when the player has time, quicker balls when they have an opponent on them. [...]. it's not simply that Xavi never misplaces a pass so it doesn't reach a team-mate, it's that he never misplaced a pass so the team-mate does the wrong thing with it." [3]

A short essay is often an introduction to an idea. A good idea will allow its followers to expand on top of that strong foundation. Thus, a 1000-word essay will eventually lead to many 6000-word papers. Around ten years ago, my mentor usually published long and technical works that focused on a long period of Vietnam economy [4], an entire aspect of entrepreneurship [5], or deep exploration of a new concept [6]. Recently, as he has aged, his focus switched to a short but concise presentation of ideas, be it scientific research [7], retraction [8], or environment [9]. This development is quite natural; only by doing the longer works can he have enough experience to arrive at the shorter works. At the moment, as he has an army of minions (me) around, his short pass is so good that I can hardly mess up the next move.

Thinking is also bursting. The idea often comes in wave and then slowly comes away. Thus, 1000 words capture the essence of your bursting idea faster. Thanks to the Internet, you can also archive and keep track of all your ideas. These are your collection of elevator pitches. Who knows where these ideas will go to? After five ideas, then 10 , then 50 , then 100 more, you have a whole weapon inventory. That would be a fantastic scenario for any researcher. Considering six times 1000 equals 6000, you can also break down your 6000word essay into a collection of six 1000-word papers. In that way, you can find your comfort in writing. 
So, this paper has 688 words.

\section{References}

[1] Pain, E. (2016). How to (seriously) read a scientific paper. Science, doi:10.1126/science.caredit.a1600047

[2] Ball, P. (2017). It's not just you: science papers are getting harder to read. Nature, doi:10.1038/nature.2017.21751.

[3] Cox, M. (2020). Reconsidered: Just how good was Xavi in Barcelona's 6-2 win at Real Madrid?. The Athletic. Retrieved from https://theathletic.co.uk/1908016/2020/07/05/xavi-barcelona-real-madrid6-21

[4] Chính, P. M., \& Hoàng, V. Q. (2009). Kinh tế Việt Nam: Thăng trầm và đột phá. Nxb Chính trị Quốc gia, Hà Nội.

[5] Vuong, Q. H., \& Tran, T. D. (2009). The cultural dimensions of the Vietnamese private entrepreneurship. The IUP Journal of Entrepreneurship and Development, 6(3), 54-78.

[6] Vuong, Q. H., \& Napier, N. K. (2015). Acculturation and global mindsponge: an emerging market perspective. International Journal of Intercultural Relations, 49, 354-367.

[7] Vuong, Q. H. (2019). Breaking barriers in publishing demands a proactive attitude. Nature Human Behaviour, 3(10), 1034-1034.

[8] Vuong, Q. H. (2020). Reform retractions to make them more transparent. Nature, 582(7811), 149.

[9] Vuong, Q. H. (2021). The semiconducting principle of monetary and environmental values exchange. Economics and Business Letters, 10(3), 1-9. 